УДК 599.742.13, 636.7

\title{
Demographic Description of Domestic Dogs Population (Omsk, Russia)
}

\author{
Marat T. Makenov ${ }^{\text {a* }}$ and Saule K. Bekovab \\ ${ }^{a}$ Omsk Research Institute of Natural Focal Infections \\ 7 Mira, Omsk, 644080, Russia \\ ${ }^{b}$ National Research University Higher School of Economics \\ 9/11 Myasnickaya Str., Moscow, 101000, Russia
}

Received 08.05.2015, received in revised form 12.05.2015, accepted 18.08.2015

The aim of this article was to describe population of owned dogs in Omsk (Russia). The article includes data on the abundance, age and sex ratio, breeds and size of owned dogs. In addition, we studied freeranging dogs. We conducted door-to-door survey of dog owners using stratified two-stage random sample. A total of 1583 households were interviewed and $23 \%$ of them were found to be dog owning households with a higher proportion in one-story residential area (72\%), than in the multi-storey residential area (11\%). The overall number of dogs in Omsk was estimated to be 78 774, dog density was $911 \mathrm{dogs} / \mathrm{km}^{2}$. About $27 \%$ of owned dogs was always allowed to roam freely in the one-storey area; in multi-storey area this practice is extremely rare (2\%). The ratio of male to female dogs in the multi-storey area was 1:1. In the area of one-storey buildings owners prefer males (62.5\%). The average age of the population was 3.8 years. In the multi-storey area of Omsk owners have mostly purebred dogs, preferring decorative medium and small dogs. In the one-storey area $51 \%$ of owners have mongrel dogs and among the purebred dogs they prefer watchdogs and guard dogs.

Keywords: owned dogs, abundance, sex ratio, age structure, breeds.

DOI: $10.17516 / 1997-1389-2015-8-3-362-372$.

C) Siberian Federal University. All rights reserved

* Corresponding author E-mail address: mmakenov@gmail.com 


\title{
Демографическая характеристика \\ домашних собак г. Омска
}

\author{
М.Т. Макенов ${ }^{\text {a* }}$, С.К. Бекова ${ }^{\sigma}$ \\ ${ }^{a}$ Омский НИИ природно-очаговых инфекиий \\ Роспотребнадзора \\ Россия, 644080, Омск, пр. Мира, 7 \\ ${ }^{6}$ НИУ Высшая шккола экономики \\ Россия, 101000, Москва, ул. Мясниикая, 9/11
}

В статье представлены результаты исследования численности владельческих собак 2. Омска, половозрастного, породного состава, размеров собак. Изучены собаки полувольного содержания. Информация о владельческих собаках была получена с помощью поквартирного опроса владельцев. Для этого была построена территориально-стратифицированная двухступенчатая выборка общим объёмом 1583 домохозяйства. В г. Омске собак содержат в 23,2 \% домохозяйств: в одноэтажной зоне - в 71,5\%, в многоэтажной - в 10,8 \% домохозяйств. Численность домашних собак в г. Омске мы оцениваем 78774 ос. Плотность населения домашних собак в г. Омске составила 910,6 ос/км². В одноэтажной зоне 26,8 \% владельцев содержат собак на свободном выгуле, в многоэтажной зоне такая практика встречается крайне редко - 2 \%. В многоэтажной зоне соотношение полов среди домашних собак составляет примерно 1:1, без существенных различий. В зоне одноэтажной застройки жители явно предпочитают содержать самчов - 62,5\%. Возрастная структура владельческих собак в одноэтажной и многоэтажной зонах примерно одинаковая, средний возраст составил 3,8 года. В многоэтажной зоне г. Омска владельиь содержат преимущественно породистых собак, отдавая предпочтения некрупным по размеру декоративным породам. В одноэтажной зоне 51,2 \% владельиев содержит беспородных собак, а среди породистых отдают предпочтение служебным и сторожевым породам.

Ключевые слова: домашние собаки, численность, половой состав, возрастной состав, nородный состав.

Изучение населения домашних собак крупного города представляет большой интерес для эпизоотологических, эпидемиологических и экологических исследований. Сведения о численности собак в городе, о половозрастном составе позволяют рассчитать показатели заболеваемости различных эпизоотий, сравнивать полученные значения в динамике, изучить факторы, влияющие на этот процесс (Костылева, 2000; Хожаева, 2001; Снегирёв, 2005).
Исследования домашних собак представляют интерес и для эпидемиологических работ. Подробное описание населения собак дает возможность оценить ситуацию по антропозоонозным инфекциям и инвазиям и спланировать профилактические мероприятия. Такой подход был использован при исследовании бешенства в Танзании (Kaare, Cleaveland, 1996; Gsell et al., 2012), Кении (Kitala et al., 2001), Таиланде (Kongkaew et al., 2004), Шри- 
Ланке (Kumarapeli, Awerbuch-Friedlander, 2009).

Цель данной работы: изучить численность и плотность населения домашних собак г. Омска, охарактеризовать тип содержания собак, половозрастной и породный состав.

\section{Материалы и методы}

Работа проводилась в г. Омске в маеавгусте 2014 г. Информацию о владельческих собаках мы получили с помощью поквартирного опроса владельцев. Для этого была построена территориальностратифицированная двухступенчатая выборка (Макенов, Бекова, 2015).

Опрос был разделён на два этапа. Первый этап включал в себя короткий опросный лист (7-13 вопросов), выборка составила 1583 домохозяйства. Генеральной совокупностью здесь выступали все домохозяйства города. При территориальной стратификации мы разделили жилую часть города на две зоны: многоэтажную и одноэтажную, для каждой из которых были построены отдельные подвыборки (Макенов, Бекова, 2015). Для многоэтажной зоны объём выборки составил 1260 домохозяйств, для одноэтажной зоны - 323 домохозяйства. В рамках этого этапа мы оценили количество домохозяйств с собаками и половозрастной состав питомцев.

Второй этап включал опрос только владельцев собак по расширенному опросному листу (68 вопросов). В этом случае генеральная совокупность была определена как все домохозяйства города, в которых содержат собак, - её объём выявили на первом этапе. Объём выборки составил 321 домохозяйство с собаками (далее - ДХС). В рамках данного этапа был получен основной эмпирический материал: демографические характеристики популяции собак и распространённые практики их содержания.
При изучении возрастного состава мы использовали данные только по собакам 2013 года рождения и старше, особи 2014 года рождения из анализа были исключены.

\section{Результаты и обсуждение}

Численность собак

В ходе проведённого исследования было установлено, что в г. Омске в $23,2 \%$ домохозяйств (дов. интервал 95 \%: 21,1-25,3 \%) содержат хотя бы одну собаку (табл. 1). В жилой одноэтажной зоне собак имеют в 71,5 \% домохозяйств (дов. интервал $95 \%: 66,4-76,6 \%$ ), а в жилой многоэтажной - в 10,8 \% домохозяйств (дов. интервал 95\%: 9,1-12,6 \%) - разница достоверна при $\mathrm{p}<0,001\left(\chi^{2}=534,66 ; \mathrm{df}=1\right)$.

При подсчёте абсолютной численности собак важно было учесть тот фактор, что в некоторых домохозяйствах могут содержать больше одной собаки. Исследуя эту возможность, мы установили, что большинство владельцев г. Омска содержит одну собаку 80,9\% (дов. интервал $95 \%$ : 79,0-82,8 \%). В одноэтажной зоне жители чаще, чем в многоэтажной, заводят более одной собаки $\left(\chi^{2}=19,19\right.$; $\mathrm{df}=4 ; \mathrm{p}=0,001)$.

Полученные данные позволили оценить численность домашних собак в г. Омске 78774 ос. (дов. интервал 95 \%: 76518 - 81 030), что соответствует значению 0,17 ос/домохозяйство, или 1,23 ос/ДХС (табл. 1). Плотность населения домашних собак в г. Омске составила 910,6 ос/км² (дов. интервал 95 \%: 884 936 oc/Kм²).

Полученный нами результат по количеству собак в г. Омске согласуется с данными общероссийского исследования, проведённого фондом «Общественное мнение» в 2006 г.: в мегаполисах собак содержат $11 \%$ россиян, в больших городах - $31 \%$, в малых - $44 \%$, а на селе - 70 \% (Шмерлина, 2008). Зона жилой одноэтажной застройки в городе по своим 
Таблица 1. Численность домашних собак в г. Омске

\begin{tabular}{|l|c|c|c|}
\hline \multicolumn{1}{|c|}{ Параметр } & Многоэтажная зона & Одноэтажная зона & Город в целом \\
\hline Доля ДХС, \% & 10,8 & 71,5 & 23,2 \\
\hline $\begin{array}{l}\text { Количество собак: } \\
\text { ос. }\end{array}$ & 51296 & 27478 & 78774 \\
ос/км & 1104,8 & 685,6 & 910,6 \\
ос/дх & 0,12 & 0,94 & 17 \\
ос/ДХС & 1,08 & 1,32 & 80,9 \\
\hline Доля ДХС (\%), в которых содержат: & & & 19,1 \\
1 собаку & 92,6 & 74,0 & \\
2 и более собак & 7,4 & 26,0 & 10,5 \\
\hline Количество собак полувольного & & & 95,2 \\
содержания: & 2,0 & 26,8 & 183,5 \\
\% от всех ДХС & 22,5 & & \\
ос/км & & & \\
\hline
\end{tabular}

Примечание: дХ - домохозяйство, ДХС - домохозяйство, в котором содержат собак.

Таблица 2. Численности домашних собак в разных городах (по литературным данным)

\begin{tabular}{|c|c|c|c|c|}
\hline \multirow{2}{*}{ Город, страна } & \multirow{2}{*}{ Доля ДХС, \% } & \multicolumn{2}{|c|}{ Количество собак } & \multirow{2}{*}{$\begin{array}{c}\text { Доля ДХС, в которых } \\
\text { содержат одну собаку, \% }\end{array}$} \\
\hline & & $\mathrm{oc} / \mathrm{KM}^{2}$ & oc/дx & \\
\hline $\begin{array}{l}\text { Города области Кокимбо, } \\
\text { Чили }^{1}\end{array}$ & $46,0-48,0$ & $1509-2380$ & $0,7-0,8$ & 69 \\
\hline $\begin{array}{l}\text { Города провинции Терамо, } \\
\text { Италия }^{2}\end{array}$ & 32,7 & - & 1,4 & 73 \\
\hline Меридо, Мексика ${ }^{3}$ & 72,8 & 1163 & 1,2 & - \\
\hline Иринга, Танзания ${ }^{4}$ & 13,3 & 334 & 0,3 & - \\
\hline Города Канады ${ }^{5}$ & 32,3 & - & - & - \\
\hline Перт, Австралия ${ }^{6}$ & 37,2 & - & - & - \\
\hline Сидней, Австралия ${ }^{7}$ & 33,4 & - & - & - \\
\hline
\end{tabular}

Примечание: 1 - Acosta-Jamett et al., 2010; 2 - Slater et al., 2008; 3 - Ortega-Pacheco et al., 2007; 4 - Gzell et al., 2012; 5 Perrin, 2009; 6 - Wood et al., 2005; 7 - Toribio et al., 2009.

условиям (типу застройки, инфраструктуре) во многом схожа с сельскими населёнными пунктами, по количеству ДХС в этой зоне также наблюдается сходство с сёлами.

В других странах количество домохозяйств, в которых содержат собак, варьирует в пределах 13-73 \% (табл. 2). Исследователи из Чили (Acosta-Jamett et. al., 2010) выявили, что в крупных городах доля ДХС существенно меньше, чем в малых городах и сёлах: 46-48,
52-71 и 78-96 \% соответственно. Сравнение показывает, что только в Танзании относительно небольшое количество жителей содержат собак (табл. 2), тогда как в остальных странах доля ДХС в городах не менее 30 \%. В г. Омске собак содержат существенно меньше, чем в городах других стран. Это связано с большим количеством домохозяйств в многоквартирных домах, для которых средняя доля ДХС составила всего 10,8 \%. 
Высокая плотность населения домашних собак в г. Омске обусловлена высокой плотностью застройки в многоэтажной зоне, в других странах в крупных городах плотность собак варьирует (табл. 2) от 334 ос/км² - г. Иринга, Танзания (Gsell et al., 2012), до 2380 - г. Кокимбо, Чили (Acosta-Jamett et al., 2010). В указанных городах столь высокие значения плотности могут быть обусловлены не только типом застройки, но и бо́льшим количеством собак в одном ДХС. В г. Омске только в 19,1 \% ДХС содержат более одной собаки, в многоэтажной зоне - ещё меньше - 7,4 \% ДХС. В городах других стран этот показатель выше: в Италии - 27 \% (Slater et al., 2008), в Чили $31 \%$ (Acosta-Jamett et al., 2010), в г. Меридо (Мексика) на одно ДХС приходится в среднем 1,6 собак (Ortega-Pacheco et al., 2007).

\section{Тип содержания собак}

В городах России распространена практика содержания собак на свободном выгуле (Березина, 2002; Рахимов, Шамсувалеева, 2012; Ivanter, Sedova, 2008): такие собаки имеют возможность покидать пределы домохозяйства без сопровождения хозяина. Авторы применяют различные термины для обозначения собак этой экологической группы, мы будем использовать термин «собаки полувольного содержания» (Макенов, 2007). Одной из задач исследования было определить, какое количество горожан содержат собак на свободном выгуле. Для этого мы разработали несколько вопросов об особенностях содержания собак. Статус «особь полувольного содержания» мы присваивали, если собака имела возможность покидать пределы домохозяйства без сопровождения человека один раз в месяц и чаще.

В результате было установлено, что в одноэтажной зоне в 26,8 \% ДХС (дов. интервал $95 \%$ : 21,8-31,8 \%) содержат собак на свободном выгуле, в многоэтажной зоне та- кая практика содержания практически отсутствует - в $2 \%$ ДХС (дов. интервал $95 \%$ : $0,0-7,0 \%)-\chi^{2}=54,8 ; \mathrm{df}=1 ; \mathrm{p}<0,01$ (табл. 1).

Плотность популяции собак полувольного содержания в многоэтажной зоне составила 22,5 ос/км², в одноэтажной зоне - 183,5 ос/км². Данный показатель значительно превышает плотность популяции свободноживущих собак, полученный нами для одноэтажной зоны г. Омска в 2005 г. (Макенов, Кассал, 2014). Такое существенное отличие объясняется тем, что не все собаки полувольного содержания имеют возможность в любое время покинуть домохозяйство, некоторые владельцы отпускают своего питомца погулять только по вечерам или в выходные дни. Понятно, что собаки с непостоянным свободным выгулом не будут попадать в поле зрения учётчика при маршрутном учёте численности, именно поэтому полученная по результатам опроса плотность популяции таких собак существенно превышает плотность, полученную по данным маршрутного учёта.

В городах других стран также описано явление полувольного содержания собак: в Италии $13 \%$ домашних собак содержатся на свободном выгуле (Slater et al., 2008), в г. Баучи (Нигерия) - в 58 \% ДХС (Atumanet al., 2014). В Чили исследователи выявили тенденцию увеличения доли собак полувольного содержания в зависимости от типа населённого пункта: в крупных городах (cities) в 27,4 \% ДХС содержат собак на свободном выгуле, в небольших городах (towns) - в 50,5\%, в сёлах (rural) - 66,6\% (Acosta-Jamett, 2009). Данная закономерность объясняет и выявленную нами относительно невысокую долю собак полувольного содержания в г. Омске: практика содержания собак на свободном выгуле распространена преимущественно в одноэтажной застройке, которая по своим условиям схожа с сельскими населёнными пунктами. 


\section{Половозрастная структура}

Было выявлено, что половое соотношение собак в одноэтажной и многоэтажной зонах г. Омска значимо отличаются $-\chi^{2}=7,37$; $\mathrm{df}=1 ; \mathrm{p}=0,007$ (рис. 1). В многоэтажной зоне соотношение полов среди домашних собак составляет примерно 1:1 (табл. 3). В зоне одноэтажной застройки жители явно предпочитают содержать самцов - 62,5 \% самцов (дов. интервал $95 \%$ : 57,2 -67,8\%) против 37,5 \% самок (дов. интервал $95 \%$ : $32,2-42,8$ \%). За счёт такого преобладания в городе в целом соотношение полов значимо смещено в пользу самцов.

Преобладание самцов в половом составе владельческих собак прослеживается также в городах Танзании (Gsell et al., 2012), Чили (Acosta-Jamett et al., 2010), Нигерии (Atuman et al., 2014), Ирландии (Downes et al., 2009), Италии (Slater et al., 2008). Возможно, эта общая тенденция объясняется тем, что содержать самок более хлопотно и требует от хозяев дополнительных усилий по контролю репродуктивного поведения своего питомца.

Среди собак полувольного содержания доля самцов составила $62 \%$, доля самок 38 \%, наблюдаемое отклонение от соотношения 1:1 недостоверно $-\mathrm{p}=0.23$ (binomial test).

Из всех домашних собак г. Омска 7,7 \% кастрированы/стерилизованы, среди самцов $5,8 \%$, среди самок - 9,8 \%, разница недостоверна $\left(\chi^{2}=2,22 ; \mathrm{df}=1 ; \mathrm{p}=0,14\right)$. Анализ показал, что владельцы собак одноэтажной зоны значительно реже кастрируют/стерилизуют своих питомцев, чем владельцы многоэтажной зоны - 3,2 и 10,0 \% соответственно $\left(\chi^{2}=5,32\right.$; $\mathrm{df}=1 ; \mathrm{p}=0,02)$.

Доля стерилизованных/кастрированных собак в г. Омске значительно ниже, чем в городах развитых стран: в Ирландии и Канаде этот показатель составил 47,3 \% (Downes et al., 2009) и 69 \% (Perrin, 2009) соответственно.
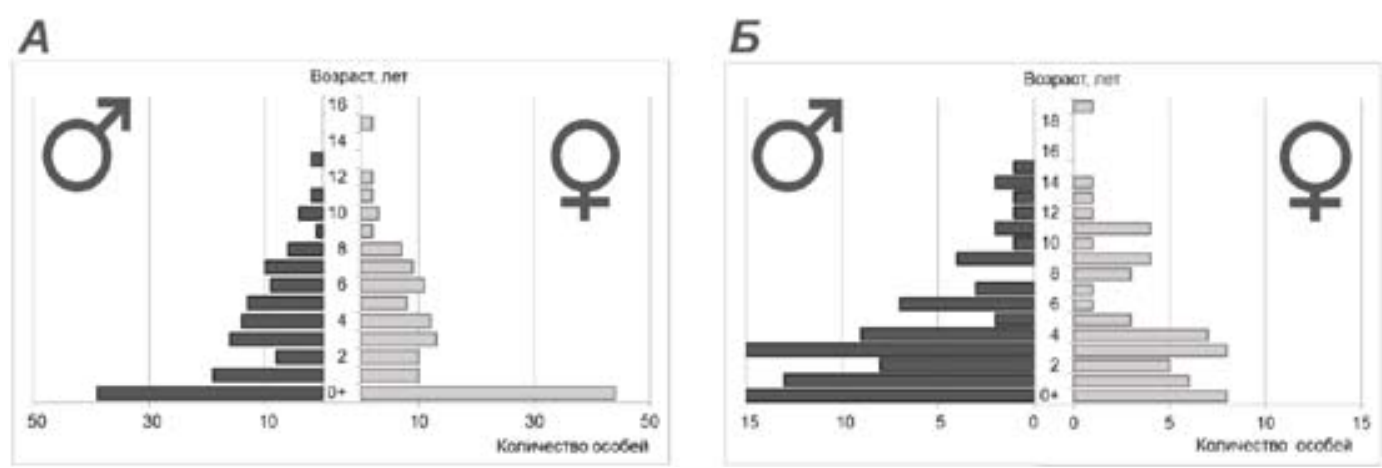

Рис. 1. Половозрастной состав домашних собак г. Омска в многоэтажной (А) и в одноэтажной (Б) зонах

Таблица 3. Половой состав домашних собак г. Омска

\begin{tabular}{|l|c|c|}
\hline \multicolumn{1}{|c|}{ Тип застройки } & Самцы & Самки \\
\hline Многоэтажная застройка & $51,0 \%$ & $49,0 \%$ \\
\hline Одноэтажная застройка & $62,5 \% * *$ & $37,5 \% * *$ \\
\hline Всего & $58,0 \% * *$ & $42,0 \% \%^{* *}$ \\
\hline
\end{tabular}

Примечание: ** Разница достоверна при $\mathrm{p}<0,01$ (binomial test). 
В Италии 16 \% собак стерилизовано/кастрировано, причём было установлено, что жители значительно чаще стерилизовали самок (Slater et al., 2008). В развивающихся странах количество стерилизованных/кастрированных собак меньше, чем в г. Омске: в г. Меридо (Мексика) - 3,1 \% (Ortega-Pacheco et al., 2007), в крупных городах Чили - 2-3\% (AcostaJamett et al., 2010).

Возрастная структура владельческих собак в одноэтажной и многоэтажной зонах примерно одинаковая, средний возраст составил 3,8 года, медианный возраст - 3,0 года, собаки в возрасте до 5 лет составляют 56,8 \% всей популяции. Максимальный возраст в популяции составил 19 лет (рис. 1).

В г. Омске по возрастному составу население домашних собак является относительно молодым. Близкое значение среднего возраста было отмечено в городах Чили $-4,0$ лет (Acosta-Jamett et al., 2010), в г. Иринга (Танзания) собаки моложе - средний возраст 2,2 года (Gsell et al., 2012), в г. Меридо (Мексика) - 3,1 лет (Ortega-Pacheco et al., 2007). В городах Италии и Канады собаки значительно старше - 4,8 (Slater et al., 2008) и 5,9 (Perrin, 2009) лет соответственно.

\section{Породный состав и размеры собак}

В многоэтажной зоне владельцы содержат преимущественно породистых собак, доля которых составила 81,7 \% (дов. интервал $95 \%$ : 76,7 -86,7 \%), отдавая предпочтения таким породам, как тойтерьер, такса, пудель (табл. 4). В одноэтажной зоне 51,2 \% (дов. интервал 95 \%: 42,1 -60,3 \%) владельцев содержат беспородных собак, а среди породистых отдают предпочтение немецкой, среднеазиатской и кавказской овчаркам. Таким образом, в многоэтажной зоне жители отдают предпочтения небольшим собакам декоративных пород, в одноэтажной зоне более крупным сторожевым, служебным собакам. Подобное различие продиктовано условиями содержания и функциями собаки. В многоэтажном доме собаки выполняют, в основном, функцию компаньона. В одноэтажных домах есть возможность содержать питомца во дворе, у собаки появляется сторожевая функция.

В одноэтажной зоне соотношение породные/беспородные собаки значимо отличается от такового в многоэтажной зоне $-\chi^{2}=43,6$; $\mathrm{df}=1 ; \mathrm{p}<0,01$. Из тех владельцев, кто отвечал, что у них собака принадлежит к той или иной породе, только у 45,4 \% имеется родословная собаки.

При изучении породного состава владельческих собак г. Омска мы выявили 58 различных пород. Среди породных собак г. Омска преобладают собаки следующих групп (по классификации Международной

Таблица 4. Наиболее популярные породы среди домашних собак г. Омска

\begin{tabular}{|c|l|l|l|l|l|l|}
\hline № & \multicolumn{2}{|c|}{ Многоэтажная зона } & \multicolumn{2}{c|}{ Одноэтажная зона } & \multicolumn{2}{c|}{ Город в целом } \\
\hline 1 & $\begin{array}{l}\text { Беспородные } \\
\text { собаки }\end{array}$ & $18,3 \%$ & $\begin{array}{l}\text { Беспородные } \\
\text { собаки }\end{array}$ & $51,2 \%$ & $\begin{array}{l}\text { Беспородные } \\
\text { собаки }\end{array}$ & $29,5 \%$ \\
\hline 2 & Тойтерьер & $7,7 \%$ & Немецкая овчарка & $6,3 \%$ & Такса & $6,4 \%$ \\
\hline 3 & Такса & $7,3 \%$ & Алабай & $6,3 \%$ & Тойтерьер & $5,9 \%$ \\
\hline 4 & Пудель & $4,5 \%$ & Кавказская овчарка & $5,5 \%$ & Пудель & $2,9 \%$ \\
\hline 5 & Лабрадор & $4,1 \%$ & Такса & $4,4 \%$ & Немецкая овчарка & $2,9 \%$ \\
\hline
\end{tabular}


Таблица 5. Распределение владельческих собак г. Омска по размерным группам ( \% от общего числа)

\begin{tabular}{|l|c|c|c|}
\hline \multicolumn{1}{|c|}{ Размер собак } & Многоэтажная зона & Одноэтажная зона & Город в целом \\
\hline До 4 кг & 18,8 & 4,8 & 14,0 \\
\hline $4-10$ кг & 41,6 & 25,4 & 36,1 \\
\hline $11-25$ кг & 21,6 & 35,7 & 26,4 \\
\hline $26-44$ кг & 14,3 & 20,6 & 16,4 \\
\hline Более 45 кг & 3,7 & 12,7 & 6,7 \\
\hline
\end{tabular}

кинологической федерации (FCI)): декоративные и собаки-компаньоны - 22,6 \%, терьеры - 19,4 \%, пинчеры, шнауцеры, молоссы $17,7 \%$.

В многоэтажной зоне 60,4 \% (дов. интервал $95 \%$ : 54,1 -66,7 \%) владельцев содержали маленьких и очень маленьких собак, а в одноэтажной зоне таких собак содержало $30,2 \%$ (дов. интервал $95 \%: 21,8-38,6 \%$ владельцев - различия достоверны при $\chi^{2}=36,2$; $\mathrm{df}=4 ; \mathrm{p}<0,01$ (табл. 5).

Среди собак полувольного содержания 47,1 \% являются беспородными. По размерам - реже всего на свободном выгуле содержат очень маленьких собак - $6 \%$, маленьких и средних по 29,4 \%, больших и очень больших $-20,6$ и 14,7 \% соответственно.

\section{Заключение}

Исследование домашних собак г. Омска показало существенные различия в практиках содержания, распространённых среди владельцев многоэтажной и одноэтажной зон.

Всего в г. Омске собак содержат в 23,2 \% домохозяйств. Общее количество владельческих собак в г. Омске составило 78774 особи. Жители жилой одноэтажной застройки заводят собак в 71,5 \% домохозяйств, в многоэтажной зоне значительно реже - 10,8 \%.
На свободном выгуле собак содержат в основном в одноэтажной зоне - в $26,8 \%$ всех ДХС зоны, в многоэтажной зоне этот показатель составил лишь 2,0 \% всех ДХС зоны.

Половая структура населения домашних собак г. Омска также существенно отличается в зонах с разным типом застройки. В многоэтажной зоне соотношение полов среди домашних собак составляет примерно 1:1, без существенных различий. В зоне одноэтажной застройки жители явно предпочитают содержать самцов, доля которых равна $62,5 \%$.

Проведённое исследование показало, что владельцы собак одноэтажной зоны значительно реже кастрируют/стерилизуют своих питомцев, чем владельцы многоэтажной зоны, $-3,2$ и 10,0 \% соответственно.

Анализ возрастной структуры населения домашних собак г. Омска в многоэтажной и одноэтажной зонах не выявил существенных отличий. Средний возраст собак составил 3,8 года.

В многоэтажной зоне г. Омска владельцы содержат преимущественно породистых собак, отдавая предпочтения некрупным по размеру декоративным породам. В одноэтажной зоне 51,2 \% владельцев содержат беспородных собак, а среди породистых - отдают предпочтение служебным и сторожевым породам. 
Исследование выполнено при финансовой поддержке РФФИ в рамках научного проeкma № 14-04-32130.

\section{Список литературы}

1. Макенов М.Т., Бекова С.К. (2015) Опыт построения территориальной выборки при исследовании домашних собак крупного города. Ветеринарный врач 4: 56-61. [Makenov M.T., Bekova S.K. (2015) Stratified sampling for the survey of urban dog. The Veterinarny Vrach journal 4: 56-61. (Abstract in English)].

2. Березина Е.С. (2002) Экология собак городских популяций. Классификация экологических групп, численность, популяционная структура групп, коммуникации (на модели г. Омска и области). Ветеринарная патология 1: 132-135. [Berezina E.S. (2002) Ecology of urban dogs population. A classification of ecological groups, abundance, population structure of groups, communication (on the model of Omsk and Omsk region). Veterinarnaya patologiya 1: 132-135 (in Russian)].

3. Костылева О.А. (2000) Эпизоотология и усовершенствование мер борьбы с инфекционными болезнями собак в условиях крупного промышленного города: автореф. ... дис. канд. биол. наук. Барнаул. 16 с. [Kostyleva O.A. (2000) Epizooiology and improvement of measures to combat infectious diseases of dogs in a large industrial city: Extended abstract of Ph.D. Thesis. Barnaul. 16 p. (in Russian)]

4. Макенов М.Т. (2007) Экологическая характеристика популяций синантропных собакпарий: автореф. дис. ... канд. биол. наук. Омск. 16 с. [Makenov M.T. (2007) Ecological characteristic of free-ranging dogs population: Extended abstract of Ph.D. Thesis. Omsk. 16 p. (in Russian)].

5. Макенов М.Т., Кассал Б.Ю. (2014) Исследование популяции свободноживущих собак г. Омска. Журнал Сибирского федерального университета. Биология 7(1): 87-98. [Makenov M.T., Kassal B.Yu. (2014) Study of free-range and stray dog population in Omsk. Journal of Siberian Federal University. Biology 7 (1): 87-98 (Abstract in English)].

6. Рахимов И.И., Шамсувалеева Э.Ш. (2012) Особенности классификации бездомных собак. Вестник Чувашского государственного педагогического университета им. И.Я. Яковлева 2-1: 131-136. [Rahimov I.I., Shamsuvaleeva E.Sh. (2012) Peculiarities of homeless dogs classification. I. Yakovlev Chuvash State Pedagogical University Bulletin 2-1: 131-136 (in Russian)].

7. Снигирёв С.И. (2005) Влияние агроклиматических условий региона на развитие эпизоотического процесса чумы и парвовирусного энтерита собак. Сибирский вестник сельскохозяйственной науки 3: 103-106. [Snegirev S.I. (2005) Influence of agro-climatic conditions of the region for the development of epizootic canine distemper and canine parvovirus. Sibirskiy vestnik sel'skokhozyaysvennoy nauki 3: 103-106 (in Russian)].

8. Хожаева И.Г. (2001) Чума и парвовирусный энтерит собак в условиях крупного промышленного города: Эпизоотология, клиника, иммунология и меры борьбы: автореф. ... дис. канд. биол. наук. Барнаул. 16 с. [Khozhaeva I.G. (2001) Canine distemper and canine parvovirus in a large industrial city: Epizooiology, clinics, immunology, treatment. Extended abstract of Ph.D. Thesis. Barnaul. 16 p. (in Russian)]. 
9. Шмерлина И. (2008) О любви к собакам и не только... Социальная реальность 1: 40-48. [Shmerlina I. (2008) It's about the love to dogs and other... Social'naya real'nost' 1: 40-48 (in Russian)]

10. Acosta-Jamett G., Cleaveland S., Cunningham A.A., Bronsvoort B.M.deC. (2010) Demography of domestic dogs in rural and urban areas of the Coquimbo region of Chile and implications for disease transmission. Preventive Veterinary Medicine 94: 272-281.

11. Acosta-Jamett G. (2009) The role of domestic dogs in diseases of significance to humans and wildlife health in central Chile: Ph.D. Thesis. The University of Edinburgh, The Institute of Zoology: U.K. 223 p.

12. Atuman Y.J., Ogunkoya A.B., Adawa D.A.Y., Nok A.J., Biallah M.B. (2014) Dog ecology, dog bites and rabies vaccination rates in Bauchi State, Nigeria. International Journal of Veterinary Science and Medicine 2(1): 41-45.

13. Downes M., Canty M.J., More S.J. (2009) Demography of the pet dog and cat population on the island of Ireland and human factors influencing pet ownership. Preventive Veterinary Medecine 92(1-2): 140-149. doi:10.1016/j.prevetmed.2009.07.005.

14. Ivanter E.V., Sedova N.A. (2008) Ecological monitoring of urban groups of stray dogs: an example of the city of Petrozavodsk. Russian Journal of Ecology 39(2): 105-110. DOI: 10.1007/s11184-0082005-5

15. Gsell A.S., Knobel D.L., Cleavland S., Kazwala R.R., Vounatsou P., Zinsstag J. (2012) Domestic dog demographic structure and dynamics relevant to rabies control planning in urban areas in Africa: the case of Iringa, Tanzania. BMC Veterinary Research 8: 236.

16. Kaare M., Cleaveland S. (1997) Targeting rabies control in the Serengeti: the rationale and design of a domestic dog vaccination campaign. Proceedings of the Fourth International Conference of the Southern and Eastern African Rabies Group. Nairobi, Kenya, 4-6 March 1997. P. 4-10.

17. Kitala Ph., McDermott J., Kyule M., Gathuma J., Perry B., Wandeler A. (2001) Dog ecology and demography information to support the planning of rabies control in Machakos District, Kenya. Acta Tropica 78(3): 217-230.

18. Kongkaew W., Coleman P., Pfeiffer D.U., Antarasena C., Thiptara A. (2004) Vaccination coverage and epidemiological parameters of the owned-dog population in Thungsong District, Thailand. Preventive Veterinary Medicine 65: 105-115.

19. Kumarapeli V., Awerbuch-Friedlander T. (2009) Human rabies focusing on dog ecology - A challenge to public health in Sri Lanka. Acta Tropica 112: 33-37.

20. Ortega-Pacheco A., Rodriguez-Buenfil J.C., Bolio-Gonzalez M.E., Sauri-Arceo C.H., JiménezCoello M., Forsberg C.L. (2007) A survey of dog populations in Urban and rural areas of Yucatan, Mexico. Anthrozoos 20(3): 261-274. doi:10.2752/089279307X224809.

21. Perrin T. (2009) The business of urban animals survey: The facts and statistics on companion animals in Canada. Canadian Veterinary Journal 50: 48-52.

22. Slater M.R., Di Nardo A., Pediconi O., Dalla Villa P., Candeloro L., Alessandrini B., Del Papa S. (2008) Cat and dog ownership and management patterns in central Italy. Preventive Veterinary Medicine 85(3-4): 267-294. doi:10.1016/j.prevetmed.2008.02.001. 
23. Toribio J.A., Norris J.M., White J.D., Dhand N.K., Hamilton S.A., Malik R. (2009) Demographics and husbandry of pets cats living in Sydney, Australia: Results of cross-sectional survey of pet ownership. Journal of Feline Medicine and Surgery 11-6: 449-461.

24. Wood L., Giles-Corti B., Bulsara M. (2005) The pet connection: Pets as a conduit for social capital? Social Science and Medicine 61: 1159-1173. 